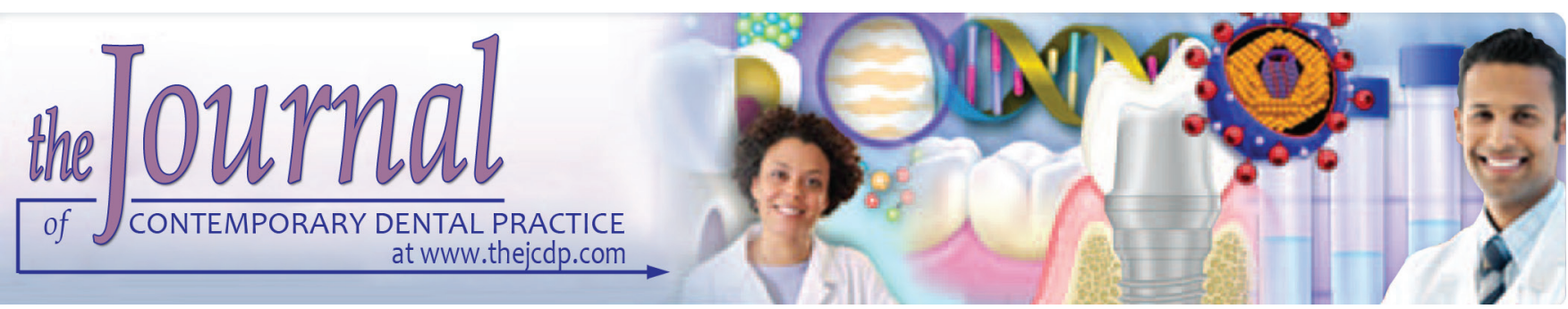

\title{
Children using Day Nurseries' Facilities can be Associated with more Risk to Nonnutritive Sucking Habits
}

\author{
${ }^{1}$ Fabiana BT Alves, ${ }^{2}$ Denise S Wambier, ${ }^{3}$ Jenny HA Alvarez, ${ }^{4}$ José CF da Rocha, ${ }^{5}$ Thais R Kummer \\ ${ }^{6}$ Vanessa C de Castro, ${ }^{7}$ Howard Cabral, ${ }^{8}$ Vitoldo A Kozlowski Jr
}

\begin{abstract}
Introduction: This study evaluated the expression of nonnutritive sucking habits and the presence of malocclusion in children using day nurseries' facilities.

Materials and methods: The 195 children (7-40 months) attending 18 public day nurseries were evaluated clinically in Ponta Grossa, Brazil. Statistical package software was used for descriptive, univariate, bivariate, and multiple logistic regressions of the data about the socioeconomic condition, educational family status, malocclusions, and prevalence of nonnutritive sucking habits among the children.
\end{abstract}

Results: The pacifier users had a statistically significant, explanatory association with open bite [odds ratio $(O R)=10.97$; $95 \%$ confidence interval $(\mathrm{Cl}): 4.95,24.31 ; p<0.0001]$. The children older than 25 months had more open bite than younger children $(\mathrm{OR}=6.07 ; 95 \% \mathrm{Cl}: 2.81,13.11 ; \mathrm{p}<0.0001)$. Of the

\footnotetext{
1,2Department of Dentistry, Ponta Grossa State University Paraná, Brazil

${ }^{3}$ Department of Orthodontics and Pediatric Dentistry, University of São Paulo, São Paulo, Brazil

${ }^{4}$ Department of Informatics, Ponta Grossa State University Paraná, Brazil

${ }^{5}$ Department of Dentistry, Centro Universitário de União da Vitória, Paraná, Brazil

${ }^{6}$ Department of Orthodontics, Federal University of Paraná Paraná, Brazil

${ }^{7}$ Department of Biostatistics, Boston University School of Public Health, Boston University Medical Campus, Boston Massachusetts, USA

${ }^{8}$ Forsyth Institute, Harvard University, Boston, Massachusetts USA, Department of Dentistry, Ponta Grossa State University Paraná, Brazil
}

Corresponding Author: Vitoldo A Kozlowski Jr, Forsyth Institute, Harvard University, Boston Massachusetts, USA Department of Dentistry, Ponta Grossa State University Paraná Brazil, Phone: +554232203104, e-mail: vakozlowski@uepg.br children examined, $35.4 \%$ had an anterior open bite, $0.51 \%$ had posterior cross-bite, and $1.03 \%$ showed finger-sucking habits. A high frequency of pacifier-sucking habits was found (52\%), with a significant association between this habit and anterior open bite $(p<0.0001, \mathrm{OR}=7.49 ; 95 \% \mathrm{Cl}: 3.71,15.15)$. The 126 children without open bite $(36.5 \%)$ were pacifier users. There was suggestive, though nonsignificant, evidence of a difference in pacifier use by gender (males, $34 \%$; females, $46 \%$; $p=0.07)$. The 69 children with open bite $(81.16 \%)$ were pacifier users and (18.84\%) nonusers. The boys showed a slightly greater association with open bite $(\mathrm{OR}=21.33 ; 95 \% \mathrm{Cl}: 6.12$, 74.40; $p<0.0001)$ than girls $(\mathrm{OR}=5.03 ; 95 \% \mathrm{Cl}: 1.26,20.00$; $p=0.02$ ) in the age group of 25 to 40 months; however, it was not observed in younger children.

Conclusion: Pacifier use is a predictor for open bite in children from the lower socioeconomic classes using day nurseries' facilities.

Clinical significance: The parents, guardians, and caregivers working in public day nurseries should be advised to monitor nonnutritive sucking habits in order to avoid or minimize the occurrence of malocclusion. It demonstrates that the permanence of the children in day nurseries may be linked with deleterious oral habits, and it discusses strategies to minimize the occurrence of alterations in the normal occlusion.

Keywords: Cross-bite, Day care, Day nurseries, Malocclusion, Open bite, Pacifier, Socioeconomic classes, Sucking habits.

How to cite this article: Alves FBT, Wambier DS, Alvarez JHA, da Rocha JCF, Kummer TR, de Castro VC, Cabral H, Kozlowski VA Jr. Children using Day Nurseries' Facilities can be Associated with more Risk to Nonnutritive Sucking Habits. J Contemp Dent Pract 2016;17(9):721-727.

Source of support: Nil

Conflict of interest: None

\section{INTRODUCTION}

The oral area is where the first emotional contact of humans with the world occurs through breastfeeding, the 
interaction between the newborn and the mother. The first year of human life is the period known as the oral phase, during which there is a psychological development, and the mouth concentrates the functions of nutrition and important emotional perceptions. In addition to feeding, the act of sucking calms infants and provides comfort during stressful situations. During this act, all the oral structures (lips, tongue, cheeks, bones, and facial muscles) are developed and strengthened. Sucking is an inborn ability, a natural response of the species, whose basic function is feeding. However, it can be both a mechanism of the energy and tension discharge and a source of pleasure and safety. Over time, the sucking act loses its nutritious function and becomes harmful. ${ }^{1}$ The need for sucking diminishes when solid feeding is introduced, because with the eruption of the first teeth, the child is forced to retract the tongue, beginning the deglutition process without sucking. This process should be established gradually. The physiological need for sucking ceases between the ages of 9 and 12 months, while the psychological need remains for some time.

Nonnutritive sucking habits are linked to emotional and psychological states, such as moments of delight, anguish, safety, and anxiety. At first, they can contribute to establishing normal occlusion, favoring facial growth without deviation. However, when these sucking habits persist, they become deleterious. They may interfere with the development of the phonological and articulated oral structures, causing buccal alterations that can persist for a lifetime. The dummy-sucking habits have a profound influence on the anomalies in the occlusions, ${ }^{2}$ but the habits of sucking fingers, oral breathing, biting objects and lips, lingual interference, onicophagic anxiety, and bruxism are all abnormal habitual patterns, and the frequency, intensity, and duration of these habits play an important role in the development of malocclusion.

The risks and benefits of the pacifier are discussed thoroughly in the scientific literature, which reports contrasting opinions about whether or not it should be used. It is believed that incorrect pacifier use is harmful to the normal development of occlusion, increasing the risk of otitis media ${ }^{3}$ and favoring early weaning ${ }^{4}$ and atypical phonation. ${ }^{5}$ On the contrary, it is customary to offer pacifiers to newborn infants to calm them. Its use is also related to psychoemotional satisfaction during the oral phase as well as the reduction of the sudden infant death syndrome. ${ }^{6}$ It is important to stimulate breastfeeding, which provides everything an infant needs naturally, rather than reducing this practice due to early use of the pacifier. The infants that begin using a pacifier soon after birth retain this habit for 4 and 5 years, and the persistence of this habit over a long period of time correlated to factors like maternal age and education level, ${ }^{7}$ with different pacifiers ${ }^{8}$ increasing the potential for occlusion anomalities. It is believed that the removal of the pacifier before the age of 3 or 4 years favors self-correction of malocclusions, because the pattern of neuromuscular contraction has not yet been completed..$^{9}$ Additionally, the pacifiers may do less harm to dentition because the pacifier habit is often dropped spontaneously between the ages of 2 to 4 years. ${ }^{10}$ On the other hand, thumb- or fingersucking habits are more likely to persist into school-age years, causing malocclusions and sometimes requiring therapy for discontinuation. The most frequent type of malocclusion is the open bite, ${ }^{7,11,12}$ which is not always symmetrical. It may be located on the central, right, or left side, depending on the position in which the pacifier is sucked. Thumb-sucking and/or pacifier use is still a controversial and inconclusive issue, and there is some evidence that socioeconomic status and lifestyle may influence the prevalence of malocclusion. ${ }^{13-15}$ Considering the importance of this issue $\mathrm{e}^{16}$ and that the social class and economic conditions remain potent discriminators of health inequalities, ${ }^{17-19}$ the aim of this study was to verify the relationship between nonnutritive habits and malocclusions in children using day nurseries' facilities.

\section{MATERIALS AND METHODS}

This cross-sectional study examined 195 children (7-40 months) of both genders attending 18 public day nurseries in Ponta Grossa, Paraná, Brazil. After approval of the research by the Institutional Review Board of the Ponta Grossa State University, the infants' parents or legal guardians received an explanation of the purpose of the study and signed the consent form authorizing the infants' oral exam. The infants were examined under natural light using a wooden spatula for clinical oral evaluation and observation for any obvious habits. The patient's hands, lips, and tongue for evidence of habits were researched. Pacifier use, finger sucking, and other nonnutritive sucking habits were evaluated. The posterior crossbite and open bite were diagnosed in a centric relationship. The concept of anterior open bite with the absence of contact of the anterior teeth, while the posterior teeth are in occlusion, was used. The infants with posterior crossbite and/or open bite were recorded in a clinical report prepared for this research. A questionnaire was provided to the parents at home and at public day nurseries, and they were questioned about the nonnutritive sucking habits in the infants, which might influence the dental structures, such as finger sucking and similar hand pressures, fingernail biting, tongue habits, and lip or cheek habits. The socioeconomic/educational data included parents' years of education, legal family relationship, and family income. 


\section{Data Analysis}

The GraphPad Prism ${ }^{\circledR}$, BioEstat ${ }^{\circledR}$, and statistical package SAS $^{\circledR}$ System software were used for descriptive, univariate, bivariate, and multiple logistic regression with statistical analysis significance at $\mathrm{p}<0.05$. The data were analyzed by multiple logistic regression, and the chi-square test for the full and partial data set with $95 \%$ confidence interval (CI) and the odds ratio (OR) of the association between nonnutritive sucking habits, malocclusions, age, gender, and monthly income was considered. The probabilistic dependence between the selected explanatory attributes and the target variable (malocclusion) was evaluated by Pearson's chi-squared test of independence using the MASS package for R statistical software. Dependence was assumed when the p-value of this test was $<0.05$.

\section{RESULTS}

In our sample of 195 families, 95\% had a monthly income $\leq \$ 300$, with $6 \%$ without any family income (Table 1 ). Thirty-nine percent of parents were divorced or separated. Ninety-one percent of the mothers and $67 \%$ of the fathers reported that they had not finished elementary school.

In a multiple logistic regression model for open bite that included pacifier use, gender, and age group as

Table 1: Percentage distribution and cumulative percent of the 195 familiar monthly incomes

\begin{tabular}{lllll}
\hline $\begin{array}{l}\text { Monthly } \\
\text { income (\$) }\end{array}$ & Frequency & Percent & $\begin{array}{l}\text { Cumulative } \\
\text { frequency }\end{array}$ & $\begin{array}{l}\text { Cumulative } \\
\text { percent }\end{array}$ \\
\hline 0 & 12 & 6.15 & 12 & 6.15 \\
100 & 97 & 49.74 & 109 & 55.90 \\
200 & 46 & 23.59 & 155 & 79.49 \\
300 & 30 & 15.38 & 185 & 94.87 \\
400 & 10 & 5.13 & 195 & 100.00 \\
\hline
\end{tabular}

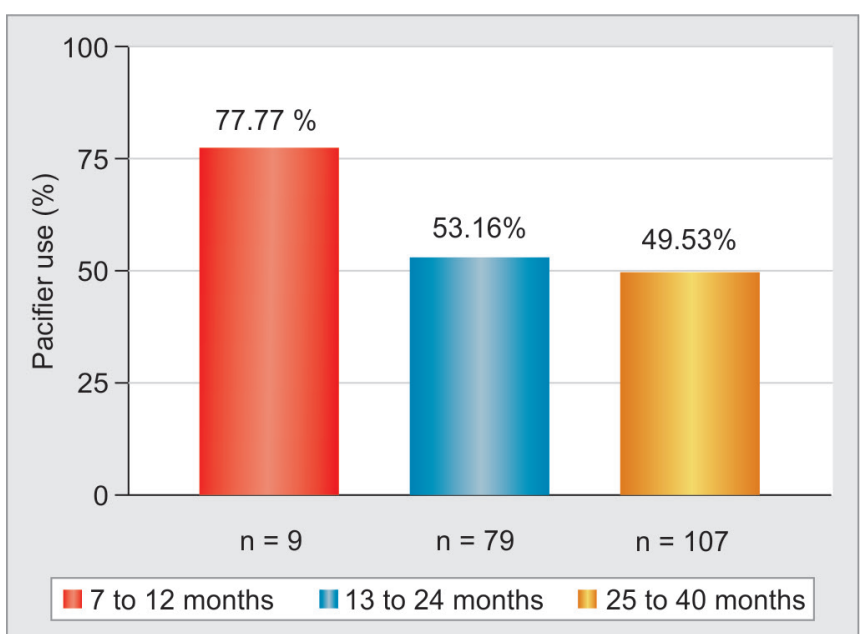

Graph 1: Distribution of pacifier use in public day nurseries per age group $(n=195 ; p=0.26$, chi-square test) explanatory variables found that pacifier use had a statistically significant association with open bite $(\mathrm{OR}=10.97$; 95\% CI: 4.95, 24.31; $\mathrm{p}<0.0001)$. In this model, children older than 25 months were found to have more open bite than younger children $(\mathrm{OR}=6.07 ; 95 \% \mathrm{CI}: 2.81,13.11$; $\mathrm{p}<0.0001)$, whereas gender was not significantly associated with open bite in this model (OR, girls vs boys $=1.21$; 95\% CI: 0.59, 2.48; $\mathrm{p}=0.60$ ).

Of the 195 children examined (Graph 1), overall 102 (52\%) used pacifiers (Graphs 1 and 2) and 69 (35.4\%) had an open bite (Graph 3). One female (age group 13 to 24 months) had posterior crossbite $(0.51 \%)$, while 2 (age group 13 to 24 months - 1 male and 1 female) had finger-sucking habits $(1.03 \%)$. We found that of the 102 children who used pacifiers, 55\% had open bite compared with $14 \%$ of the 93 children who did not use pacifiers (OR $=7.49 ; 95 \% \mathrm{CI}: 3.71,15.15 ; \mathrm{p}<0.0001)$, with $81.16 \%$ of the 69 children with open bite using pacifier (Graph 3). The 126 children without open bite $(36.5 \%)$ were pacifier users. Of note, pacifier use did not significantly differ by age $(p=0.28)$, and there was suggestive, though nonsignificant, evidence of a difference in pacifier use by gender (males, 34\%; females, $46 \%$; $\mathrm{p}=0.07$ ). In analyses of the data for boys and girls separately, we found that pacifier use among boys had a slightly greater association with open bite (56\% for pacifier users vs $13 \%$ for nonusers; $\mathrm{OR}=8.28$; $95 \%$ CI: 3.31, 20.72; $\mathrm{p}<0.0001)$ than did girls ( $54 \%$ for pacifier users vs $16 \%$ for nonusers; OR $=6.38$; 95\% CI: 2.10 , 19.37; $\mathrm{p}=0.0005$ ) (Graph 4). This difference, however, was markedly more pronounced in the age group of children aged 25 to 40 months. Among these 107 children, pacifier use among boys $(n=68)$ had a slightly greater association with open bite ( $80 \%$ for pacifier users vs $16 \%$ for nonusers; $\mathrm{OR}=21.33 ; 95 \% \mathrm{CI}: 6.12,74.40 ; \mathrm{p}<0.0001)$ than did girls $(n=39 ; 70 \%$ for pacifier users $v s 31 \%$ for nonusers; OR=5.03; 95\% CI: 1.26, 20.00; $\mathrm{p}=0.02)($ Graph 5).

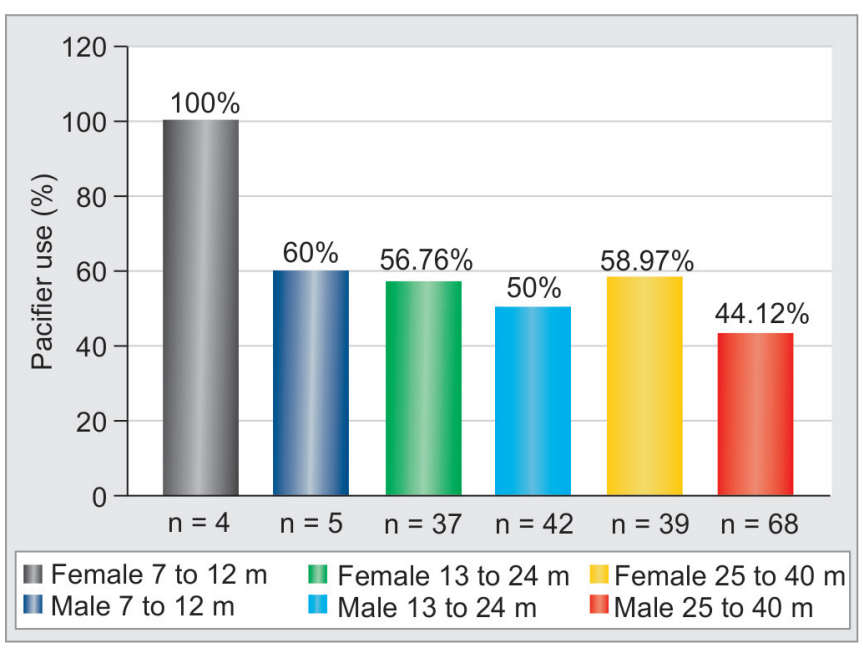

Graph 2: Distribution of pacifier use in public day nurseries by gender and age group $(n=195 ; p=0.25$, chi-square test) 


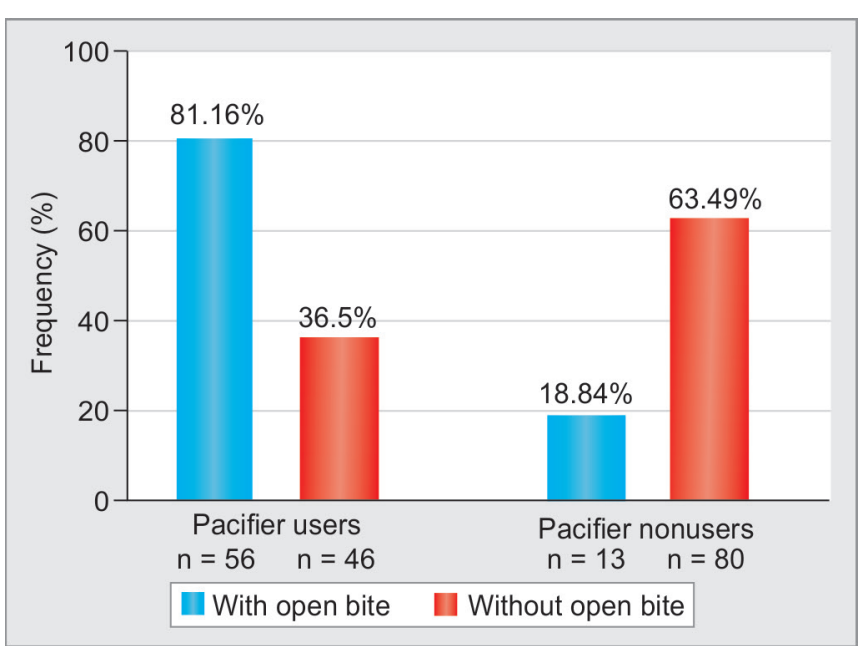

Graph 3: Distribution of the infants in public day nurseries with open bite $(n=69)$ and without open bite $(n=126)$ using pacifiers $(n=102)$ or not using pacifiers $(n=93)(p<0.0001$, chi-square test; $\mathrm{OR}=7.49 ; 95 \% \mathrm{Cl}: 3.71,15.15)$

This large a difference was not observed, however, in similar analyses of younger children.

The results of the Pearson's test of probabilistic independence were consistent with the observations above. The hypotheses of dependence associations between open bite and pacifier were supported by a p-value of $5.9 \times 10^{-9}$. For open bite and age, a dependence association was detected by obtaining a p-value of $1.6 \times 10^{-4}$. No significant dependencies were found between open bite and gender $(\mathrm{p}=0.50)$.

\section{DISCUSSION}

Deleterious oral habits are extrinsic factors that influence the development of malocclusion..$^{15}$ The literature shows a high frequency of pacifier-sucking habits, with percentages ranging from 50 to $80 \% .{ }^{18-21}$ Our results are consistent with the aforementioned report since $52 \%$ of the infants examined had this habit. However, the extension and gravity of alterations may vary according to the intensity, duration, and frequency of the habit. Previous studies demonstrated that 75 and $53 \%$ of infants in age groups 13 to 24 months and 25 to 40 months respectively, suck to sleep, ${ }^{22}$ and $77.7 \%$ of infants in the age group 7 to 12 months use bottle-feeding to sleep. ${ }^{23}$ The sucking habit is associated with a higher prevalence of malocclusion in primary dentition, such as the relationship of canine teeth and molars in class II, anterior open bite, posterior crossbite, increased overbite and overjet, increased width of the upper arch, and decreased width of the lower arch. ${ }^{7}$

The data analyzed here identified a significant correlation between pacifier sucking and anterior open bite, as has already been demonstrated by several studies. ${ }^{8,9,24}$ Our clinical evaluation found that $81.16 \%$ of the infants that had malocclusion were pacifier users and were at a 7.49-fold higher risk of developing open bite,

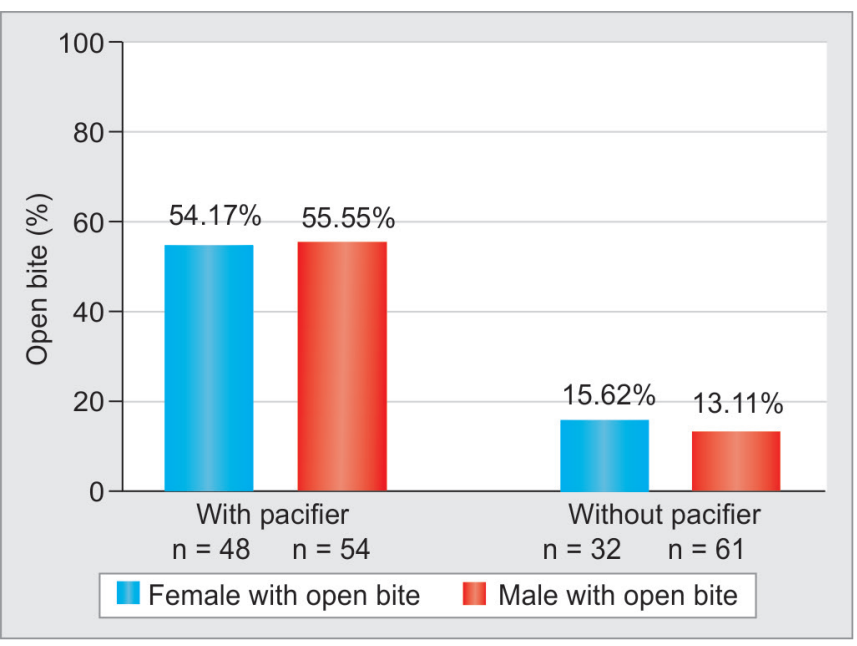

Graph 4: Distribution of open bite in public day nurseries by gender in children using or not using pacifier $(n=195 ; p<0.0001$, chi-square test)

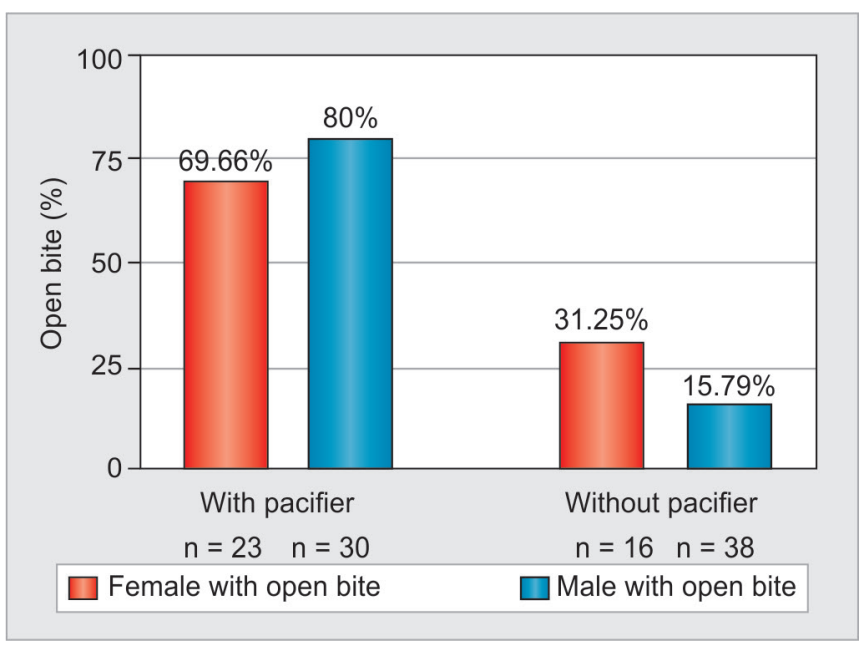

Graph 5: Distribution of open bite in public day nurseries by gender in the age group 25 to 40 months $(n=107 ; p<0.0001$, chi-square test)

with boys showing a tendency for a higher frequency of malocclusions than girls according to another report. ${ }^{12}$ The clinical evaluation suggests the possibility that some children could be more emotionally and psychologically dependent on their mothers, being influenced by the public day care environment and using pacifiers with more frequency to calm down and for comfort during stressful situations. Other researchers found 0 to $88 \%$ of infants with anterior open bite associated with pacifiersucking habits. ${ }^{7,13,19,24,25}$ The nonnutritive sucking habit contributes to the development of anterior open bite, but is not the only cause. Growth patterns, genetic characteristics, breathing and swallowing patterns, atypical deglutition, and lingual interference can also influence the development of malocclusion. Heimer et $\mathrm{al}^{24}$ showed that the facial growth patterns were not associated with the etiology of anterior open bite, supporting that malocclusions may be more acquired than inherited. 
In our study, $18.84 \%$ of the infants with open bite were nonpacifier users, while $36.5 \%$ without this malocclusion were pacifier users. This suggests that other etiological factors contribute to anterior open bite since only $1.03 \%$ of the infants showed the finger-sucking habit. There was suggestive, though nonsignificant, evidence of a difference in pacifier use by gender (males, 34\%; females, $46 \%$; $\mathrm{p}=0.07)$, similar to the data obtained by Ogaard et $\mathrm{al}^{11}$ who found sucking habits to be more frequent among girls. The data analysis showed a uniform distribution of pacifier use in the age groups and by gender, with no significant difference found between pacifier users and nonusers. If the habit had been totally abandoned in the early months or by age 2 , the 25- to 40-month age group would have shown fewer pacifier users. However, this was not observed. A longitudinal study conducted by Tornisiello Katz and Rosenblatt ${ }^{25}$ who examined 4- to 5-year-old children with the pacifiersucking habits found that the prevalence diminished from 28 to $19 \%$, while the anterior open bite declined from 72 to $59 \%$ after 1 year.

According to some researchers, oral habits can be influenced by social factors, such as working mothers, the introduction of bottle-feeding, time the infant spends in day nurseries (full- or part-time), and parents' socioeconomic and educational level. 9,14,15,17,22,23,26,27 The infants studied here attend public day nurseries full-time because their parents have full-time work. Reinke et $\mathrm{al}^{23}$ observed that $64.9 \%$ of infants in public day nurseries use bottles to sleep and $23.9 \%$ wake up every night for bottle-feeding. This may lead to an early interruption of maternal breastfeeding and the use of pacifiers. There is an association between pacifier use, shorter/exclusive duration of breastfeeding ${ }^{21,28}$ and bottlefeeding. ${ }^{2,23}$ An indirect linear relationship between breastfeeding and pacifier use demonstrated that the more the infant was breast-fed the less pacifier was used. ${ }^{20}$ In another study in which most of the infants were bottle-fed between the ages of 0 and 6 months, bottle-feeding was associated with pacifier sucking. ${ }^{29}$ An important relationship is known to exist between breastfeeding and the development of nonnutritive sucking habits. Inadequate or lack of breastfeeding may give rise to compensatory attitudes favoring the development of deleterious sucking habits, such as the nonnutritive sucking of fingers and/or pacifiers. ${ }^{8,13,21}$ Tamura et $\mathrm{al}^{30}$ found changes in the total muscle activity in breast-fed infants of different ages, while the mean suckle cycle showed no significant difference. In another study, ${ }^{31}$ children with nonnutritive sucking habits were eliminated prior to evaluating the association between methods of infant feeding and occlusion, and researchers demonstrated that the children who continued bottle-feeding at 24 months of age exhibited
$33.3 \%$ overbite, $22.2 \%$ anterior crossbite, while the open bite was $0 \%$.

Self-correction of malocclusion may also occur after oral phases; hence, it is important to consider the possibility of stopping deleterious habits in the early years of life, thereby minimizing the risk of children developing occlusion abnormalities. Some researchers ${ }^{3,32}$ agree that the ideal age for a child to stop the sucking habit is around the age of 2 or 3 , while other researchers believe age 3 or 4 is ideal. ${ }^{1,10}$ Children usually abandon the habit of pacifier sucking during the preschool period at about 4 to 5 years of age. ${ }^{25}$ If this habit persists past the age of 4 , with maturation of the neuromuscular contraction pattern, malocclusions can be perpetuated by the establishment of abnormal function. ${ }^{14}$ Thus, to minimize malocclusion, Adair ${ }^{10}$ suggests that it is advisable for the use of pacifiers to be reduced starting at age 2 and completely discontinued by or before age 4 .

In the normal development of the dental arches, the bone and muscle structures of the stomatognathic system interact harmoniously and the presence of deleterious oral habits may cause deviations in the development of occlusion, without influencing the cephalometric measurements. ${ }^{24}$ The high prevalence of pacifier use and anterior open bite found in the children of this study leads us to agree with other researchers ${ }^{10,20,24}$ that this habit merits special attention, especially when it becomes a real problem. In reality, the presence of this sucking habit is not single because Ozawa et $\mathrm{al}^{33}$ showed a prevalence of $70.7 \%$ open bite in children with $27.2 \%$ of finger and $16.8 \%$ pacifier-sucking habits, while we found just $1.03 \%$ finger-sucking habit, not one unusual sucking habit, ${ }^{34}$ and $18.84 \%$ open bite in nonpacifier users. The geographical and population characteristics are important too, for example, Retnakumari and Cyriac $^{35}$ evaluated 350 children aged 12 to 36 months attending day care centers in Trivandrum, Kerala, and found that pacifier use was limited to very few children (only 5.1\%), while Sriram et $\mathrm{l}^{36}$ reported that anterior spaced dentition was a common feature in the children of Chennai (73.6\%) and Hyderabad (74.1\%), without data about nonnutritive habits.

Preventive attitudes are simpler and more effective than corrective treatment (orthopedic and orthodontic). Additionally, specific strategies and methods like emotional and psychological support to reduce the use of pacifiers need to be tested, since there are no studies with this objective in the literature. ${ }^{21}$ Therefore, it is better to promote good practices and provide parents and professional caregivers at public day nurseries with early information about nonnutritive habits, in order to minimize the occurrence of malocclusions. ${ }^{23,37}$

In summary, the present study demonstrated that pacifier use has a strong dependence with open bite 
and, therefore, can be viewed as an explanatory variable associated with open bite in children from the lower socioeconomic classes using day nurseries' facilities, indicating that the risk of development of anterior open bite is fine in pacifier users. Additionally, the data collected during this study suggest that there are other etiological factors contributing to malocclusion. More studies are necessary to improve the diagnostics of different conditions may influence the prevalence of anterior open bite in children using public day nurseries. Consequently, the parents, guardians, and caregivers working in public day nurseries should be advised to monitor nonnutritive sucking habits because the permanence of the children to day nurseries may be linked with deleterious oral habits, in order to avoid or minimize the occurrence of malocclusion. The emotional, psychological, political, geographical, socioeconomic, and educational parameters associated with different communities are examples of additional factors that can be included and recommended in future studies, especially because the children's oral habits may be influenced by caregivers' behavior in the day nurseries, and it needs to be investigated. Additionally, future investigations are necessary to discuss strategies in order to diminish the occurrence of alterations in normal occlusion of children using nurseries' facilities.

\section{REFERENCES}

1. Turgeon-O'Brien H, Lachapelle D, Gagnon PF, Larocque I, Maheu-Robert LF. Nutritive and nonnutritive sucking habits: a review. ASDC J Dent Child 1996 Sep-Oct;63(5):321-327.

2. Duncan K, McNamara C, Ireland AJ, Sandy JR. Sucking habits in childhood and the effects on the primary dentition: findings of the Avon longitudinal study of pregnancy and childhood. Int J Paediatr Dent 2008 May;18(3):178-188.

3. Warren JJ, Levy SM, Kirchner L, Nowak AJ, Bergus GR. Pacifier use and the occurrence of otitis media in the first year of life. Pediatr Dent 2001 Mar-Apr;23(2):103-107.

4. Newman J. Breastfeeding problems associated with the early introduction of bottles and pacifiers. J Human Lact 1990 Jun;6(2):59-63.

5. Wadsworth SD, Maul CA, Stevens FJ. The prevalence of orofacial myofunctional disorders among children identified with speech and language disorders in grades kindergarten through six. Int J Orofac Myol 1998;24:1-19.

6. Soxman JA. Non-nutritive sucking with a pacifier: pros and cons. Gen Dent 2007 Jan-Feb;55(1):59-62; quiz 63, 79-80.

7. Warren JJ, Bishara SE, Steinbock BS, Yonezu T, Nowak AJ. Duration of nutritive and non-nutritive sucking behaviors and their effects on the dental arches in the primary dentition. Am J Orthod Dentofacial Orthop 2002 Apr;121(4):347-356.

8. Zardetto CGC, Rodrigues CRMD, Stefani FM. Effects of different pacifiers on the primary dentition and oral myofunctional structures of preschool children. Pediatr Dent 2000 Nov-Dec;24(6):552-560.

9. Levine RS. Briefing paper: oral aspects of dummy and digit sucking. Br Dent J 1999 Feb;186(3):108.
10. Adair SM. Pacifier use in children: a review of recent literature. Pediatr Dent 2003 Sep-Oct;25(5):449-458.

11. Ogaard B, Larsson E, Lindsten R. The effect of sucking habits, cohort, sex, intercanine arch widths, andbreast- or bottlefeeding on posterior cross-bite in Norwegian and Swedish 3-year-old children. Am J Orthod Dentofacial Orthop 1994 Aug;106(2):161-166.

12. Carvalho JC, Vinker F, Declerck D. Malocclusion, dental injuries and dental anomalies in the primary dentition of Belgian children. Int J Paediatr Dent 1998 Jun;8(2):137-141.

13. Karjalainen S, Rönning $\mathrm{O}$, Lapinleimu H, Simell O. Association between early weaning, non-nutritive sucking habits and occlusal anomalies in 3-year-old Finnish children. Int J Paediatr Dent 1999 Sep;9(3):169-173.

14. Peres KG, Latorre MRDO, Sheiham A, Peres MA, Victora CG, Barros FC. Social and biological early life influences on the prevalence of open bite in Brazilian 6-year-olds. Int J Paediatr Dent 2007 Jan;17(1):41-49.

15. Hebling SR, Cortellazzi KL, Tagliaferro EP, Hebling E, Ambrosano GM, Meneghim MC, Pereira AC. Relationship between malocclusion and behavioral, demographic and socioeconomic variables: a cross-sectional study of 5-yearolds. J Clin Pediatr Dent 2008 Fall;33(1):75-79.

16. Sexton S, Natale R. Risks and benefits of pacifiers. Am Fam Physician 2009 Apr;79(8):681-685.

17. Fadel CB, Kozlowski VA Jr. Diet and oral hygiene as caries predictors in early childhood. UFES Rev Odontol 1999;1:66-77.

18. Tomasi E, Victora CG, Olinto MT. Use of pacifiers in children: patterns and determinants. J Pediatr (Rio J) 1994 May-Jun;70(3):167-171.

19. Ahammed ARY, Shetty V, Panda AK, Gunda S, Pradhan D, Husain N, Gugwad S. Prevalence of malocclusion among 12 to 15 years age group orphan children using dental aesthetic index. J Contemp Dent Pract 2013 Jan;14(1):111-114.

20. Degan VV, Puppin-Rontani RM. Prevalence of pacifier-sucking habits and successful methods to eliminate them - a preliminary study. J Dent Child (Chic) 2004 May-Aug;71(2):148-151.

21. Parizoto GM, Parada CM, Venâncio SI, Carvalhaes MA. Trends and patterns of exclusive breastfeeding for under-6-month-old children. J Pediatr (Rio J) 2009 May-Jun;85(3):201-208.

22. Cuman V, Moreira CS, Wambier DS, Kummer TR, Kozlowski VA Jr. Correlation among carious lesions, bacterial plaque, mouth hygiene and the use of the night bottle in babies. J Dent Res 2002;81(Spec Iss A):2753, A345.

23. Reinke SMG, Steffens JP, Rastelli MCS, Kozlowski VA Jr, Alves FBT, Wambier DS. Relationship of the food habits and oral hygiene with experience of caries in babies on the municipal day nursery of Ponta Grossa, Paraná. Dental Sci 2010;4:18-26.

24. Heimer MV, Tornisiello Katz CR, Rosenblatt A. Anterior open bite: a case-control study. Int J Paediatr Dent 2010 Jan;20(1):59-64.

25. Tornisiello Katz CR, Rosenblatt A. Non-nutritive sucking habits and anterior open bite in Brazilian children: a longitudinal study. Pediatr Dent 2005 Sep;27(5):369-373.

26. Wambier DS, Kozlowski VA Jr, Kummer TR, Alves FT, Moreira CS, Cuman V. Study of periodontal alterations in babies with complete and incomplete deciduous dentition. RPG Rev Pós Grad 2004;11:377-382.

27. Kuriakose S, Prasannan M, Remya KC, Kurian J, Sreejith KR. Prevalence of early childhood caries among preschool children in Trivandrum and its association with various risk factors. Contemp Clin Dent 2015 Jan-Mar;6(1):69-73. 
28. Simard I, O’Brien HT, Beaudoin A, Turcotte D, Damant D, Ferland S, Marcotte MJ, Jauvin N, Champoux L. Factors influencing the initiation and duration of breastfeeding among low-income women followed by the Canada prenatal nutrition program in 4 regions of Quebec. J Hum Lact 2005 Aug;21(3):327-337.

29. Charchut SW, Allred EN, Needleman HL. The effects of infant feeding patterns on the occlusion of the primary dentition. J Dent Child (Chic) 2003 Sep-Dec;70(3):197-203.

30. Tamura Y, Matsushita S, Shinoda K, Yoshida S. Development of perioral muscle activity during suckling in infants: a crosssectional and follow-up study. Dev Med Child Neurol 1998 May;40(5):344-348.

31. Yonezu T, Kadoya M, Yakushiji M. Effects of prolonged breastand bottle-feeding on occlusal characteristics in the primary dentition. Ped Dent J 2005 Apr;15:176-179.

32. Scavone H Jr, Ferreira RI, Mendes TE, Ferreira FV. Prevalence of posterior crossbite among pacifier users: a study in the deciduous dentition. Braz Oral Res 2007 Jun;21(2):153-158.
33. Ozawa N, Hamada S, Takekoshi F, Shinji H. A study onnonnutritive sucking habits in young Japanese children Relationships among incidence, duration, malocclusion and nursing behavior. Pediatr Dent J 2005 Dec;15(1): 64-71.

34. Chowdhary N, Gaffur H, Sandeep, Chowdhary R. An unusual sucking habit in a child. Contemp Clin Dent 2010 Oct;1(4):249-250.

35. Retnakumari N, Cyriac G. Childhood caries as influenced by maternal and child characteristics in pre-school children of Kerala - an epidemiological study. Contemp Clin Dent 2012 Jan;3(1):2-8.

36. Sriram $\mathrm{CH}$, Priya VK, Sivakumar N, Maheshwar Reddy KR, Babu PJ, Reddy P. Occlusion of primary dentition in preschool children of Chennai and Hyderabad: A comparative study. Contemp Clin Dent 2012 Jan;3(1):31-37.

37. Vadiakas G, Oulis C, Berdouses E. Profile of non-nutritive habits in relation to nursing behavior in pre-school children. J Clin Pediatr Dent 1998 Dec;22(2):133-136. 